\title{
Organic Fertilizers and Natural Pest Control versus Chemical Fertilizers and Pesticides
}

\author{
Mohamed Ibrahim Elzagheid* \\ Jubail Industrial College, Department of Chemical and Process Engineering Technology, Saudi Arabia
}

*Corresponding author: Mohamed Ibrahim Elzagheid, Jubail Industrial College, Department of Chemical and Process Engineering Technology, Saudi Arabia

\begin{abstract}
This min review briefly describes chemical fertilizers and pesticides and their implications. It discusses the advantages of replacing pesticides with biopesticides and how deploying them can have great potential in bringing sustainability to global food production and feed security. The review also discusses how better protection of agricultural crops can be achieved by introducing modern techniques and developing novel strategies of plant protection.
\end{abstract}

Keywords: Fertilizers; Natural Organic Fertilizers; Chemical Fertilizers; Natural Pest Control; Pesticides

\section{Introduction}

The use of chemical substances especially chemical pesticides to enrich the soil for growing plants like vegetables and fruits has greatly affected the farmland ecosystem, degraded the quality of farmland and decreased the production. There is a great need for an efficient eco-agriculture to tackle some hazardous effects associated with chemical agriculture. However, there is a debate on whether organic agriculture can cover the world need especially with the large global population. High efficiency chemicals free agriculture may offer enough foods production and reduce environmental pollutions caused by the use of chemical fertilizers. Jiang Gaoming [1] suggested that this can be done by feeding cattle with bio-processed corn straw, restoring the soil fertility by manure treatment and using physical and biological methods for pest control to put an end to pesticides, chemical fertilizers and herbicides pollution. Among those solutions is to use insecttrapping lamps and organic fertilizers to improve soil. He also added that stop using plastic films, synthetic hormones, genetically modified seeds will enhance the food quality and safety.

Sujata Law [2] stated that multiple health hazards and fatalities from the widespread use of pesticides have been reported by the WHO. Intensive use and exposure to pesticides in some developing countries has led to great decline in the public health. She reported that pesticide exposure induced bone marrow aplasia is the direct manifestation of down regulated hedgehog signaling in the bone marrow microenvironment. Afo and Ushie recommended that the use of appropriate and well-maintained spraying equipment along with handling pesticides with precautions can minimize human exposure adverse effects on the environment [3].

Machiavelli and Khurana [4] added that great deal of efforts focusing on the soil biological systems and the agro-ecosystem as a whole is required because of the great challenge of agriculture supply of food due to human population increase. Alternative sources of phosphate fertilizers to supplement, or to replace in some cases, the chemical fertilizers to ensure competitive yields of crops will be of great assists. The exploration of different microbial processes contained in the soil-root interface (rhizosphere) as biofertilizers is good alternative to replace the chemical fertilizers. Adding or inoculating phosphate-solubilizing microbes (PSM) to agro-ecosystems presents promising strategy. As in the ancient times where of animal manures were used to provide phosphorous for plant growth. During those times it was difficult to understand that the organically bound phosphorous enters in the soil during the decay of natural vegetation, dead animals and from animal excretions and the role of micro flora on soil fertility was hardly understood, but now it is well understood that a large fraction of soil microbes can dissolve insoluble inorganic phosphates present in the soil and make them available to the plants. Therefore, inoculating phosphate-solubilizing microbes in agricultural and manure may lead to low cost inputs with high benefits. 
Balachandar [5] reported that plant growth promoting rhizobacteria (PGPR) stimulates plant growth through various direct and indirect mechanisms. The direct effects include dinitrogen fixation, mineral solubilization, growth hormone production, and biocontrol against soil pathogens considered as an indirect effect. He mentioned that exploring the genetic and functional diversity of these PGPRs from various agroclimatic zones, and developing them as multi-functional bioinoculants, would be a novel approach to enhance the biofertilizer use efficiency in agriculture.

Biopesticides are also gaining great interest because they are safe to environment, and bio-degradable. Thus, they are promising alternatives candidates to manage environmental pollutions. Through replacement of pesticides by biopesticides in agriculture environmental safety can be gained. Currently, the use of biopesticides is covering only $2 \%$ of the plant protectants used globally; however, there is an increasing trend of their applications in the past two decades and their world production has been estimated to be over 3,000 tons per year [6]. Environmentally safe, residue-free agriculture and growing organic food products market are considered as some of the key drivers of the biopesticide market. Worldwide use of the biopesticides is increasing steadily by $10 \%$ every year. About $90 \%$ of the microbial biopesticides are derived from just one entomopathogenic bacterium, Bacillus thuringiensis. In the 34 OECD countries about 225 microbial biopesticides are manufactured [7], and about $45 \%$ of the biopesticides are sold in the so-called NAFTA countries while Asia uses only $5 \%$ of biopesticides sold worldwide [8].

Although many countries have launched new policies to minimize the use of chemical pesticides and promote the use of biopesticides; however, biopesticides are still largely regulated by the regulations previously designed for chemical pesticides which in turn created burdensome costs on the biopesticide industry [9]. Understanding of the biopesticides mode of action, their effects and regulatory issues could boost their profile among the public, policymakers and hence enable them to realize their contributions to sustainability. As synthetic chemical pesticides are not suitable for organic food production, recently green pesticides from plant origin are given more intention. They are better alternatives to chemical pesticides if eco-friendliness, multiple mode of action against insect pests are carefully considered [10]. Generally green pesticides are eco-chemicals isolated from parts of the plants. Plants contain essential oils which are a complex mixture of volatile compounds accumulated in seeds, flowers and leaves. These essential oils contain various alcohols, cyclic alcohols, bicyclic alcohols, phenols, ketones and aldehydes which are released by the plants to protect them against herbivores and pathogens.

Introduction of modern techniques to develop novel strategies of plant protection is highly needed. One of those techniques is the application of nanotechnology as a new practice in agriculture. In particular, designing of nanoformulation of different insecticides.
Nano-insecticides can cause less environmental contamination and show enhanced efficiency reached by controlled release. They are easy/safe to handle and have reduced toxicity risks to animals. Polymer-based nanoformulations have been tested for the encapsulation of most of the insecticides. There are different forms of polymer and non-polymer-based nanoformulations that have been proposed for insecticides' encapsulation. Examples are nanocapsules, nanogels, nanofibers, nanometals and nanoemulsions [11].

\section{Conclusion}

The interest in organic farming and the use of biopesticide instead of chemical pesticides has gained great intention. Educating and training the farmers on the organic fertilizers and the biopesticides and their use will have great impact. Creating awareness among the farmers will also popularize them and increase their utilization globally. Appropriate deployment of the biopesticides and organic fertilizers will potentially bring sustainability to world agriculture for food and feed security.

\section{Acknowledgement}

The author of this article likes to thank Kimberly William for the invitation to submit a mini review to the journal of Current Investigation in Agriculture and Current Research (CIACR). The author also likes to thank JIC management team for the continuous help, encouragement and support.

\section{References}

1. Gaoming J (2017) Organic agriculture obtains both larger yield and economic benefit under the condition of none chemical pollution. Agrotechnology 6(4): 23.

2. Law S (2018) Agricultural pesticide induced bone marrow aplastic anaemia and the hedgehog signaling scenario. Environ Pollut Climate Change 2: 69 .

3. Afo ID and AO Ushie (2018) Evaluation of active ingredient, risk assessment and safety of pesticide on the life of farmers in Taraba State, Nigeria. J Environ Anal Toxicol 8: 47.

4. Machiavelli and SMP Khurana (2013) An Inoculating Potential of Phosphate-Solubilizing Microbes as Biofertilizers. J Biofertil Biopestici 4(1): 1-2.

5. Balachandar D (2012) Biofertilizers-What Next? J Biofertil Biopestici $3(4)$.

6. Kumar S, A Singh (2015) Biopesticides: Present Status and the Future Prospects. J Fertil Pestic 6(2): 1-2.

7. Hubbard M, RK Hynes, M Erlandson, KL Bailey (2104) The biochemistry behind biopesticide efficacy. Sustainable Chemical Processes 2(18).

8. Bailey KL, SM Boyetchko, T Längle (2010) Social and economic drivers shaping the future of biological control: a Canadian perspective on the factors affecting the development and use of microbial biopesticides. Biol Control 52(3): 221-229.

9. Kumar S, A Singh (2014) Biopesticides for integrated crop management: environmental and regulatory aspects. J Fertil Pestic 5: e121.

10. Raja N, G Masresha (2015) Plant Based Biopesticides: Safer Alternative for Organic Food Production. J Fertil Pestic 6: 2.

11. Das RK, SJ Sarma, SK Brar, M Verma M (2014) Nanoformulation of Insecticides - Novel Products. J Biofertil Biopestici 5: e120. 


\section{(cc) (i)}

This work is licensed under Creative

Commons Attribution 4.0 License

To Submit Your Article Click Here: Submit Article

DOI: $10.32474 /$ CIACR.2019.06.000232

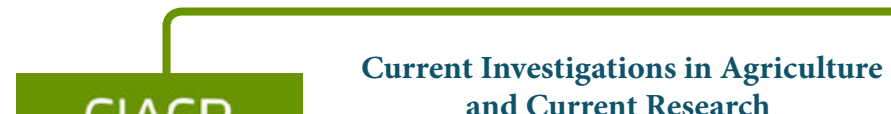
and Current Research

Assets of Publishing with us

- Global archiving of articles

- Immediate, unrestricted online access

- Rigorous Peer Review Process

- Authors Retain Copyrights

- Unique DOI for all articles 